\title{
Modeling and experimental evaluation of a small-scale fresnel solar concentrator system
}

\author{
Luis Rafael Sanchez Vega*
}

\begin{abstract}
The purpose of this study was to evaluate the overall effectiveness of a small-scale, low cost, versatile solar concentrator suitable for the needs of single individuals. The system consisted of a spot-type fresnel lens, and a solar absorber sized for moderate temperature range $\left(80-250^{\circ} \mathrm{C}\right)$ applications. Simple and inexpensive materials were chosen for the construction of the tracking system, frame, and absorbers. The thermodynamic properties of the system were determined from theoretical and experimental estimates of temperature and pressure. Efficiencies as high as $50 \%$ were estimated form irradiance and heat losses measurements. The study proved the feasibility and cost effectiveness of the small-scale solar concentrator prototype for varied applications such as boiling water, solar cooking, and autoclaves.
\end{abstract}

Keywords: Fresnel lens, Solar energy, Solar concentrator, Solar heat transfer efficiency, Film boiling, Water distillation

\section{Background}

Applications of solar power to thermal applications are commonly categorized in low $\left(<80{ }^{\circ} \mathrm{C}\right)$-, moderate $\left(80-250{ }^{\circ} \mathrm{C}\right)-$, and high $\left(>250{ }^{\circ} \mathrm{C}\right)$-temperature ranges. Because sunlight has low-energy density, solar concentrators are mainly used for applications above the low range. Competing technologies include Fresnel (Tian and Zhao 2013), Parabolic trough concentrators (Xie et al. 2011), Concentrated Solar Power (CSP), and Photovoltaic (PV) Solar Panels (Yinghao 2011). Additionally, Solar Thermoelectricity Systems (STA), dye-sensitized solar cell (DSPV) and concentrated photovoltaic systems are in use. An innovative $40 \mathrm{~m}^{2}$ parabolic dish concentrator tower (Airlight Energy Co. and IBM 2014) is estimated to generate $12 \mathrm{KW}$ of electrical power and $20 \mathrm{KW}$ of heat on a sunny day. These amounts are based on $80 \%$ efficiency at $1 \mathrm{KW} / \mathrm{m}^{2}$ solar irradiance. The dish, to be introduced by 2017 , will consist of 36 elliptic mirrors concentrating the sun at $1 / 2000$ the area.

\footnotetext{
*Correspondence: Ir.sanchez@ucdenver.edu; Irafaelsv@comcast.net Department of Mechanical Engineering, College of Engineering and Applied Science, University of Colorado Denver, 1200 Larimer St. Denver, CO 80217, USA
}

Although Fresnel lenses showed significant advantages among parabolic, hyperboloid, total internal reflection, quantum dot, and high-concentration devices (Madhugir and Karale 2012), solar tracking was pointed out as a main drawback for fresnel applications. Solar tracking challenges were also reported for commercial applications ranging from 0.33 to $30 \mathrm{MW}$ (Kumar et al. 2015).

Among the technologies reviewed, small Fresnel concentrators may provide thermal energy adequate to individual or single household usage. To be cost effective, the system would require low investment, minimum maintenance, of easy usage, and the flexibility to be used in several applications. A system aimed to meet these constraints was designed by the author (Fig. 1). The main components are commonly found in published solar systems: a PMMA (polymethyl methacrylate) Fresnel lens of around $0.5-1 \mathrm{~m}^{2}$ area, a frame, and a tracking system. Nevertheless, the usage of these systems is not extensive. Motors and controllers used for tracking increase the cost and require accessibility to electric power grids or to solar panel systems. A second limitation may arise from the thermal characteristics of the Fresnel system. The high levels of thermal energy concentrated by the lens are

\section{Springer}

C 2016 Sanchez Vega. This article is distributed under the terms of the Creative Commons Attribution 4.0 International License (http://creativecommons.org/licenses/by/4.0/), which permits unrestricted use, distribution, and reproduction in any medium, provided you give appropriate credit to the original author(s) and the source, provide a link to the Creative Commons license, and indicate if changes were made. 


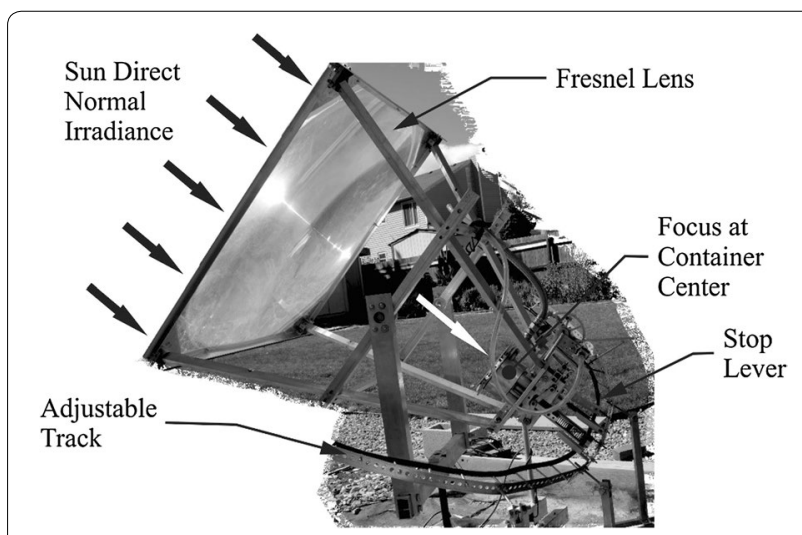

Fig. 1 Fresnel system

alike to stoves or furnaces. Fully unattended applications require higher cost designs aimed at transferring heat continuously without compromising safety.

\section{Methods}

The design of the fresnel system was simplified by manually positioning the track and the frame prior to exposure to the sun. Once positioned, the system was designed to track the sun mainly unattended for the day. Daily reposition may restrict its usage to partly supervised or timed applications, but the advantages were significant. The system operated without electric motors, controllers, or feedback tracking. It did not need access to external electric power. The system was low cost, very low maintenance, and easy reparability, using economical and universally available mechanical components. These benefits may appeal to users without access to inexpensive electric energy, provided that the cost and the efficiency of the system are kept within acceptable levels.

The objective of this study was to assess the capabilities, efficiency, and easiness of operation of the proposed low-cost semi-manual fresnel system. The heat from the lens was collected by water: (1) in open containers for water boiling applications; (2) in closed containers for applications with water and vapor under pressure. Collected data included irradiance, pressure, and temperature at various locations. The efficiency of the system was calculated from estimates of the amount of heat collected by the water. This study did not intend to optimize the efficiency based on best performance components which were not cost effective or universally available.

The lens concentrated the sun irradiance on a circular spot around 2600 smaller, with a measured transmittance loss of around $11 \%$. Because the lens is made of concentric grooves etched in the PMMA material (BHLens 2014; Fresnel Technologies 2014), some spherical aberration was expected. This effect, detrimental for imaging applications, was not as critical for heat-collecting applications where the proper design of the absorber was paramount. Nonimaging heat collectors, reported to additionally capture diffuse light, would be expected to be more efficient. However, under sunny skies diffuse light constitutes a typically small (10-12\%) percentage of the solar energy captured by direct light (NREL radiation database 2014). The small difference in energy captured may be offset by the availability and low cost of the fresnel lens.

The azimuth and the altitude (or elevation) angles at the test location are published by USNO (United States Naval Office 2014), and by NREL (2014). The data were used to mechanically adjust the tracking mechanism using a digital angular level. Tracking can be adjusted to \pm 0.2 degree at the supported points, and typically remains within \pm 0.6 degree at locations between supports (Fig. 2).

The frame is guided by a mechanism enforcing positive contact between the lever and the track. The brake mechanism can vary according to the application. It can be manually operated at any time, or timed at desired, specific intervals. Figure 1 shows a mechanism suited to reach temperatures and pressures for autoclave applications. As the water is heated, the pressure increases inside the container, causing a rod to move. The rod releases the stop lever, which frees the frame to move along the track and away from the sun's rays.

\section{Results and discussion}

The efficiency of the system was assessed for two experimental cases; (1) water boiling at atmospheric pressure, (2) water under pressure.

For the first case, water was boiled through a folded copper sheet installed inside the container (Fig. 3). The beam was focused through the glass window, where it contacted the copper interface, causing the temperature to increase. The frame remained in place while the angular position of the sun relative to the frame changed from

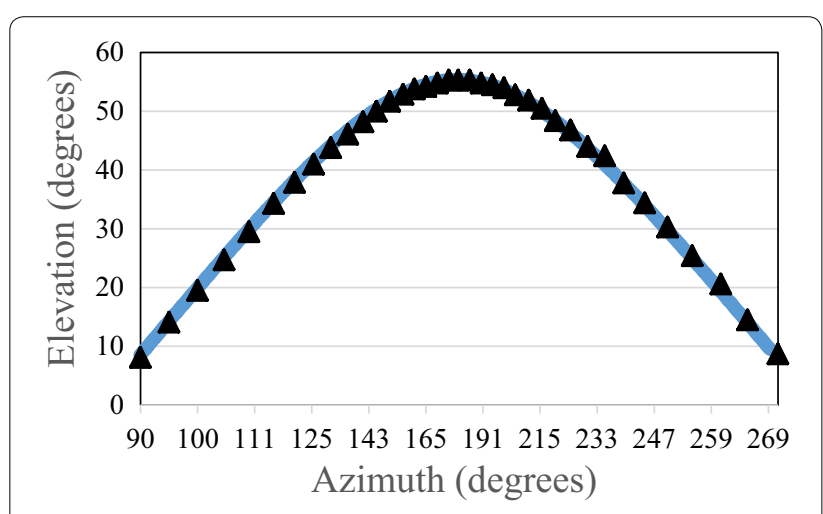

Fig. 2 Frame locations along the sun path (September 9, 2015) 


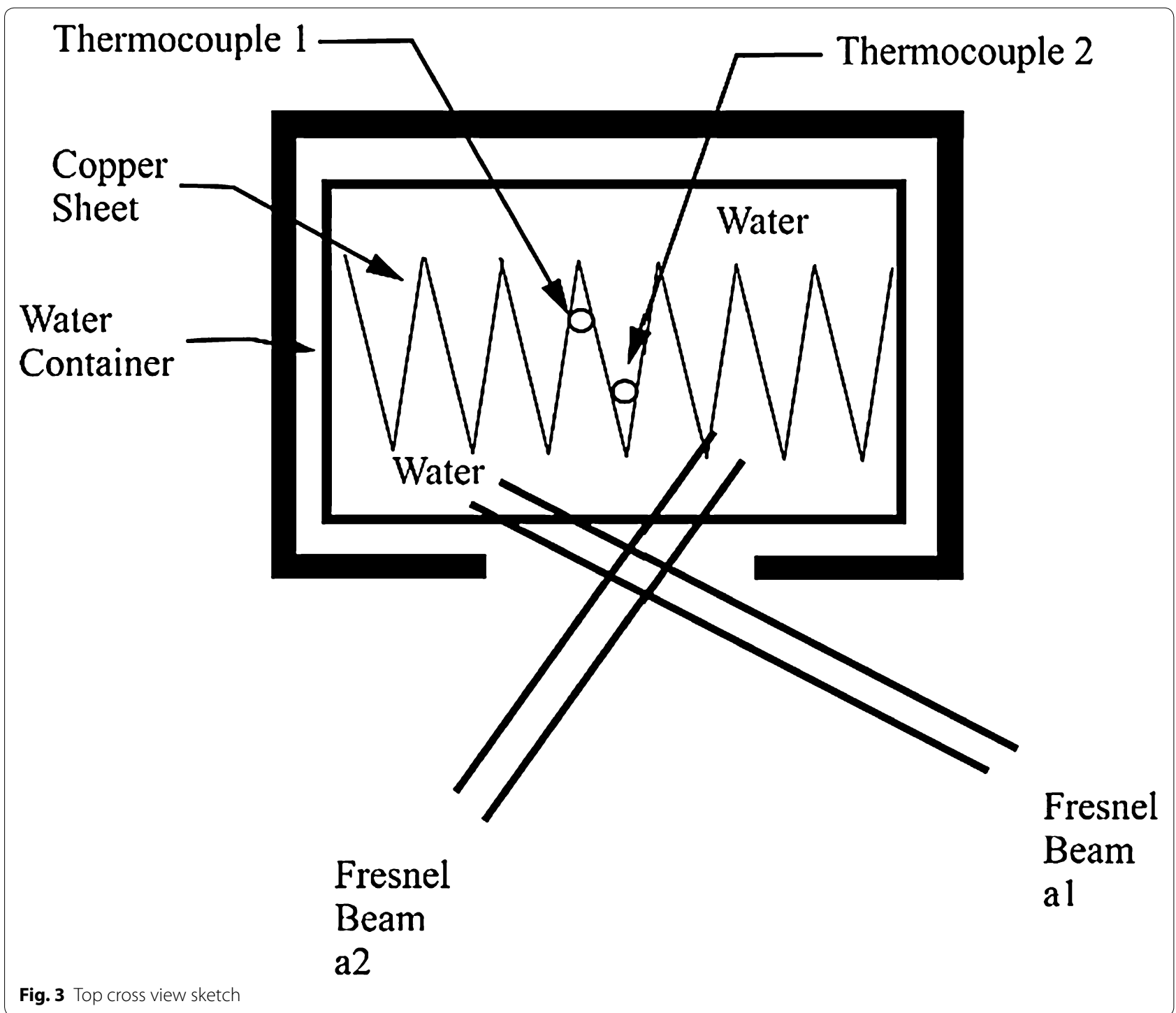

$\alpha_{1}$ to $\alpha_{2}$. Upon reaching $\alpha_{2}$, the frame rotated to a new $\alpha_{1}$ repeating the cycle every $10-13 \mathrm{~min}$. The temperature of the water was measured by thermocouples located at the front and back of the sheet.

An initial amount of $1.2 \mathrm{~kg}$ of water was heated to boiling temperatures during the time shown in Fig. 4 . Thermocouple 1 , facing the sun beam, recorded higher temperatures than Thermocouple 2 throughout testing, though the difference became significantly smaller $\left(\sim 4{ }^{\circ} \mathrm{C}\right)$ during boiling.

The Direct Normal Irradiance (DNI) at the experimental location was, on average, $1098 \mathrm{~W} / \mathrm{m}^{2}$. After $11 \%$ transmissibility losses through the lens, and about $12 \%$

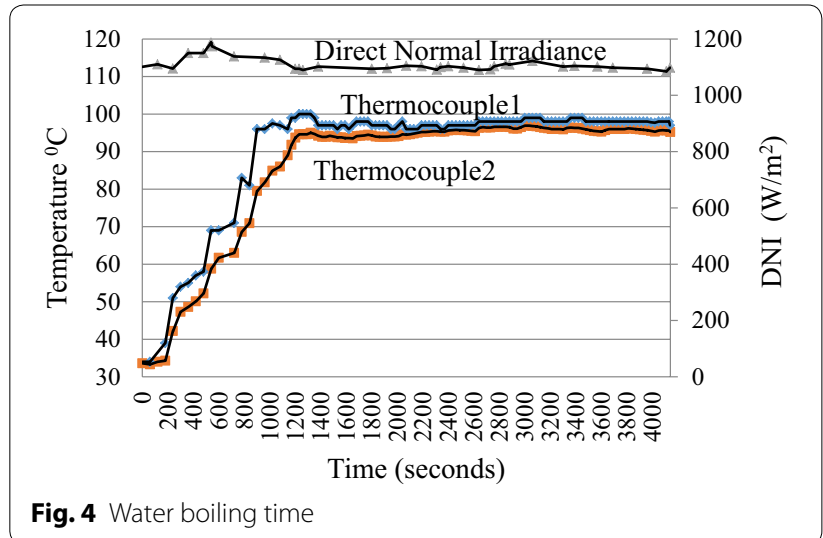


losses through the container glass window, the next flux was $q=1098(0.89)(0.88)(0.83)=713.8 \mathrm{~W}$, where $0.83 \mathrm{~m}^{2}$ is the area of the lens.

The total energy supplied during the test duration of $4145 \mathrm{~s}$ was $q=2958.5 \mathrm{~kJ}$. The amount of water loss was $498.4 \mathrm{~g}$. From water tables, the total heat transferred into the water was $1601 \mathrm{~kJ}$; or $54 \%$. Efficiencies of more sophisticated solar thermal collectors have been reported as high as 70 to $80 \%$ (Kalogirou 2004).

A second experiment consisted of pressurizing a closed container to absolute pressures in excess of $0.5 \mathrm{MPa}$. A pressure transducer and seven thermocouples were installed as shown in Fig. 5.

Thermocouples 1, 2, 3 are shielded in the cup area. TC4 and 5 are in contact with water inside the container; TC7 is symmetrically opposite to 3 , and TC6 is on the exterior wall, opposite to 5 .

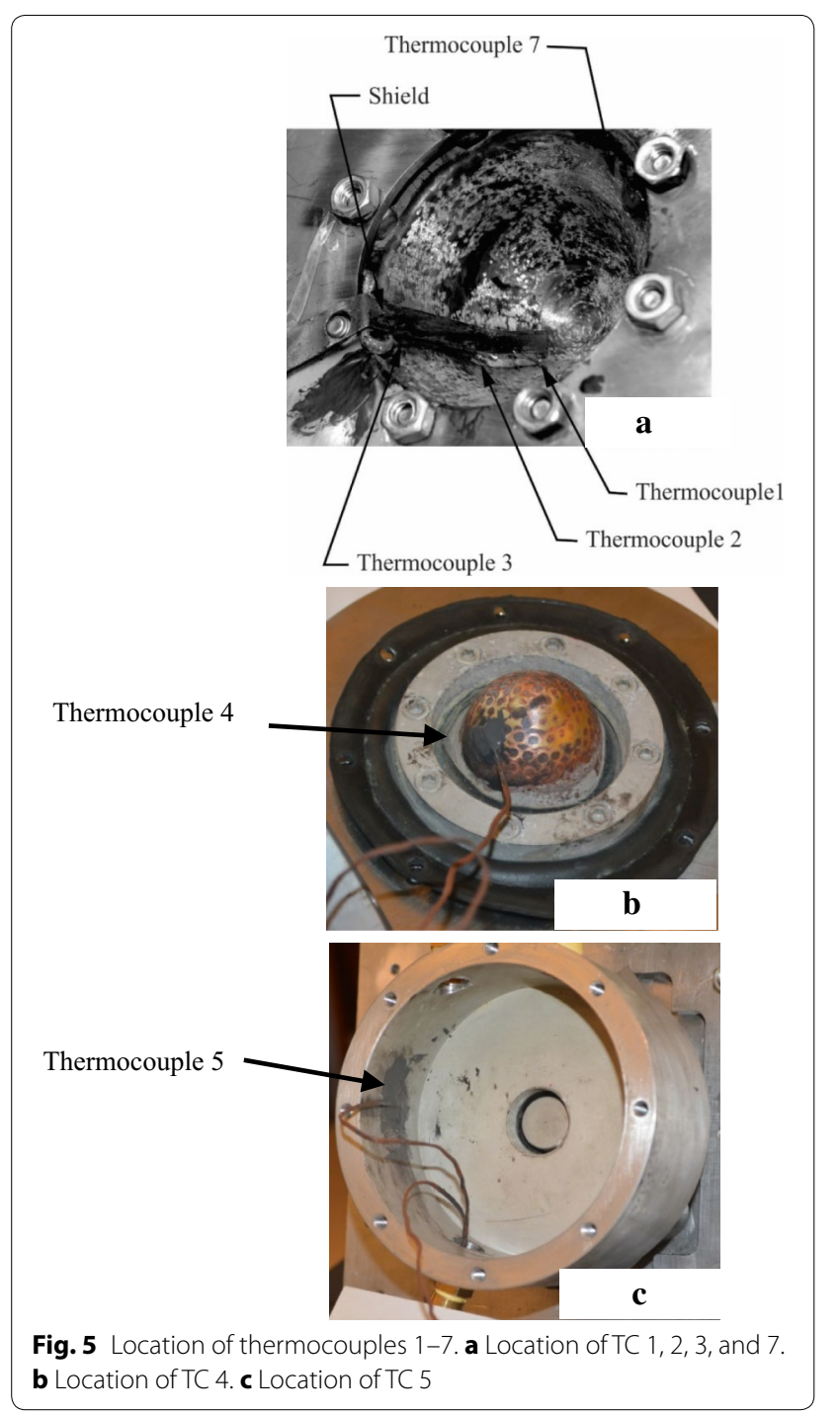

Figure 6a shows the irradiance and its effects on Thermocouple 1 and Thermocouple 2. TC 1 was nearest the center of the cup, therefore receiving the greatest solar radiation. At $908 \mathrm{~s}$, the beam became focused directly at the TC1 location, resulting in a sudden $65 \%$ temperature increase. A similar (60\%) temperature increase was observed at TC2. The change on the readings of both thermocouples can be attributed to uneven heating at the center of the cup due to the motion of the frame. Conductive heat from the center to the upper sections of the cup monotonically increased the readings for TC3 and TC7 (Fig. 6b). TC3 and TC7 readings were similar, with maximum variations of around $9{ }^{\circ} \mathrm{C}$ after $1000 \mathrm{~s}$. These TC readings indicate that, although not uniformly, the beam remained focused around the center of the cup.

Inside the container, TC4 (located at the cup wall in contact with water) was about $10{ }^{\circ} \mathrm{C}$ above TC5 (located at the container inner wall). This difference was maintained at the lower temperature range, but converged as the temperature increased. Because TC4 is approximately at the same level, but opposite to TC2, the large differences between their readings show high-thermal gradients transmitted through the cup wall. FEM contour diagrams (Fig. 7) corroborate these high gradients.

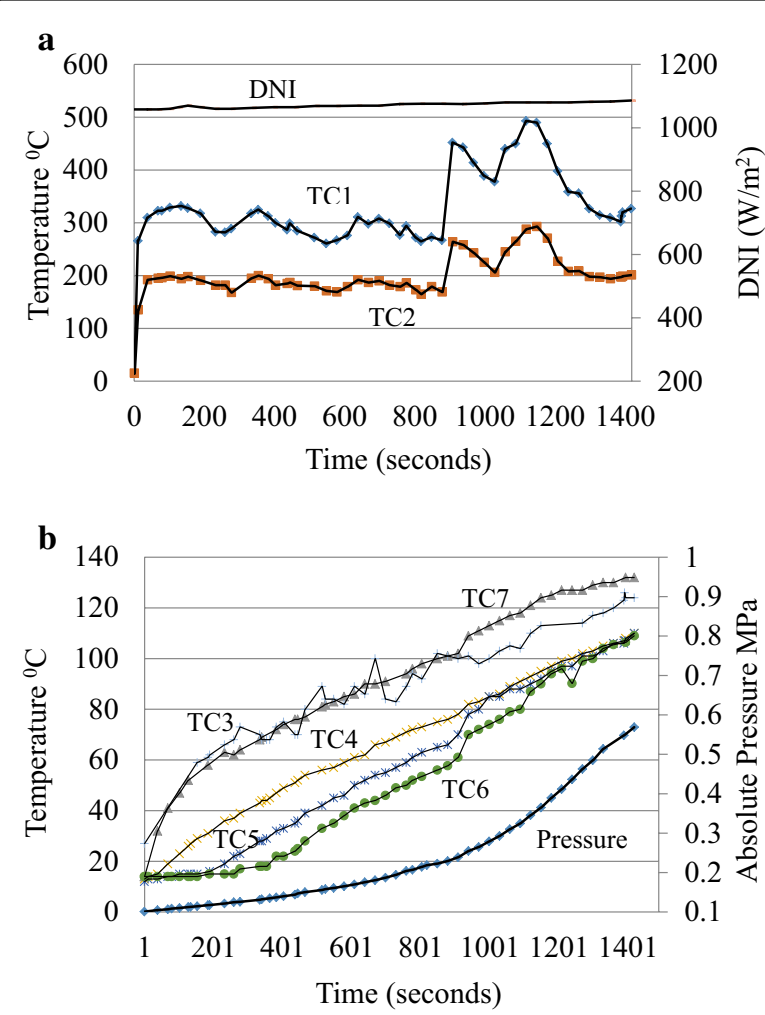

Fig. 6 Direct Normal Irradiance, absolute pressure and thermocouple readings in fuction of time. a TC1 and TC2, and DNI. b TC3-7 and absolute pressure 
The container in Fig. 1 has an internal piston that can be used as a safety valve, and also to actuate the tracking mechanism. A simplified diagram is shown in Fig. 8. The displacement of the piston increases the volume of the container. Because the spring compresses upon displacement of the piston, the spring force and thus the pressure on the fluid increases. Setting the spring adjusts the desired final temperature and pressure reached at a displacement $\delta$, where the valve opens and the vapor is released.

The initial conditions are defined at ambient temperature, atmospheric pressure, and with the container full of water. As heat is transferred, water becomes a twophase fluid mixture in equilibrium. The approach below is based on steam table data. Let

$v_{f}=$ Specific volume of the saturated liquid,

$v_{g}=$ Specific volume of the saturated vapor,

$m_{f}=$ Mass in liquid phase,

$m_{g}=$ Mass in vapor phase,

$v=$ Specific volume for the two-phase liquid and vapor phase, and

$m=$ total mass of the two-phase mixture.

The total volume is given by $m v=m_{f} v_{f}+m_{g} v_{g}$. The quality of the mixture, $x$, is given by $x=\frac{m_{g}}{m}$, Reordering:

$$
v=v_{f}+x\left(v_{g}-v_{f}\right), 0 \leq x \leq 1
$$

The force applied to the spring by the system is $F=k_{\mathrm{s}}$ $\left(\delta+\delta_{0}\right)$, where $k_{\mathrm{s}}$ is the spring constant, $\delta$ is the piston displacement, $\delta_{0}$ is the spring preload.

Monitoring the displacement, $\delta$, gives the pressure $P$ at the piston:

$$
P=\frac{F}{A_{\text {piston }}}+101,325=\frac{k_{\mathrm{s}}\left(\delta+\delta_{0}\right)}{\pi\left(\frac{d}{2}\right)^{2}}+101,325 \mathrm{~Pa}
$$

where $d$ is the piston diameter and $P$ is the absolute pressure.

With the absolute pressure (and temperature) known as a function of the displacement, we can determine from the steam tables the amount of water vaporizing with increasing pressure. The amount of heat transferred to the water-vapor mixture is given by

$$
Q_{\text {in water+vapor }}=U_{\text {water+vapor }}+W
$$

From experimental data: total mass $=m=0.51 \mathrm{~kg}$, Piston diameter $=d=1.125$ in. $=0.02858 \mathrm{~m}$, Piston area $=A=0.994$ in. $^{2}=6.4153(10)^{-4} \mathrm{~m}^{2}$, Spring constant $=k_{\mathrm{s}}=10.0 \mathrm{lbs} / \mathrm{in} .=1750 \mathrm{~N} / \mathrm{m}$, Free length $=3.61 \mathrm{in} .=0.0917 \mathrm{~m}$,
Initial compressive preload $=3.07$ in $=0.078 \mathrm{~m}$; $\delta_{0}=3.61-3.07=0.54 \mathrm{in} .=0.0137 \mathrm{~m}$, and

Final compression $=2.15$ in $=0.055 \mathrm{~m} ; \delta=3.61-$ $2.15=1.46$ in. $=0.037 \mathrm{~m}$.

Estimates from the steam tables data show very small amounts of vaporization produced as the absolute pressure is increased to $0.25 \mathrm{MPa}$, and the temperature is raised to about $126.8{ }^{\circ} \mathrm{C}$ (Table 1 ). At displacement $\delta$, the valve opens and significant vaporization takes place as the pressure drops to 1 atmosphere. The change in Enthalpy drops to $532.9-418.7=114.1 \mathrm{~kJ} /$ $\mathrm{kg}$. The latent energy at $100{ }^{\circ} \mathrm{C}$ is $2257 \mathrm{~kJ} / \mathrm{kg}$ and the mass evaporated becomes $=\frac{114.1}{2257}(0.51)=0.0258 \mathrm{~kg}$. On average, $0.21 \mathrm{~kg} / \mathrm{h}$ of water vapor is produced. The efficiency is:

$$
\text { Efficiency }=\frac{0.21}{2476.8 / 2571} 100=21.8 \%
$$

where $2476.8 \mathrm{~kJ} / \mathrm{h}$ was the energy received in $1 \mathrm{~h}$ and $2571 \mathrm{~kJ} / \mathrm{kg}$ is the amount of energy required to vaporize water from $25^{\circ} \mathrm{C}$. The work on the spring is given by:

$$
\begin{aligned}
W= & m \frac{P_{0}+P_{\text {final }}}{2}\left(v_{\text {final }}-v_{0}\right) \\
W= & 0.51 \frac{0.101325+0.250}{2} \\
& (0.001089-0.00104)=4.4 \mathrm{~J} / \text { cycle }
\end{aligned}
$$

Temperatures on the order of $130{ }^{\circ} \mathrm{C}$ using a Fresnel lens have been used for water disinfection (Awad 2012). A related application, autoclave design, requires saturated steam at $121^{\circ} \mathrm{C}$ for around $15-20 \mathrm{~min}$, or $134^{\circ} \mathrm{C}$ for 3 min (Tuttnauer USA Co. 2015). These applications were shown to be within the scope of the current prototype.

Given the high focal temperatures, the Fresnel lens must be treated with caution. Nevertheless, safety concerns have not been an issue provided that basic precautions are followed. The focal area must not be handled without properly covering the lens. Side covers protect users from unexpected movements of the focal point. A cover tarp wrapped with elastic cords provided effective protection to hail and high winds.

\section{Conclusions}

This study demonstrates the performance of a smallscale, low cost, low maintenance Fresnel solar concentrator designed to satisfy basic needs of single individuals. The theoretical and the experimental results showed that the solar thermal energy generated can be high enough for useful applications including pasteurization, autoclave design, solar cooking, and water boiling. 

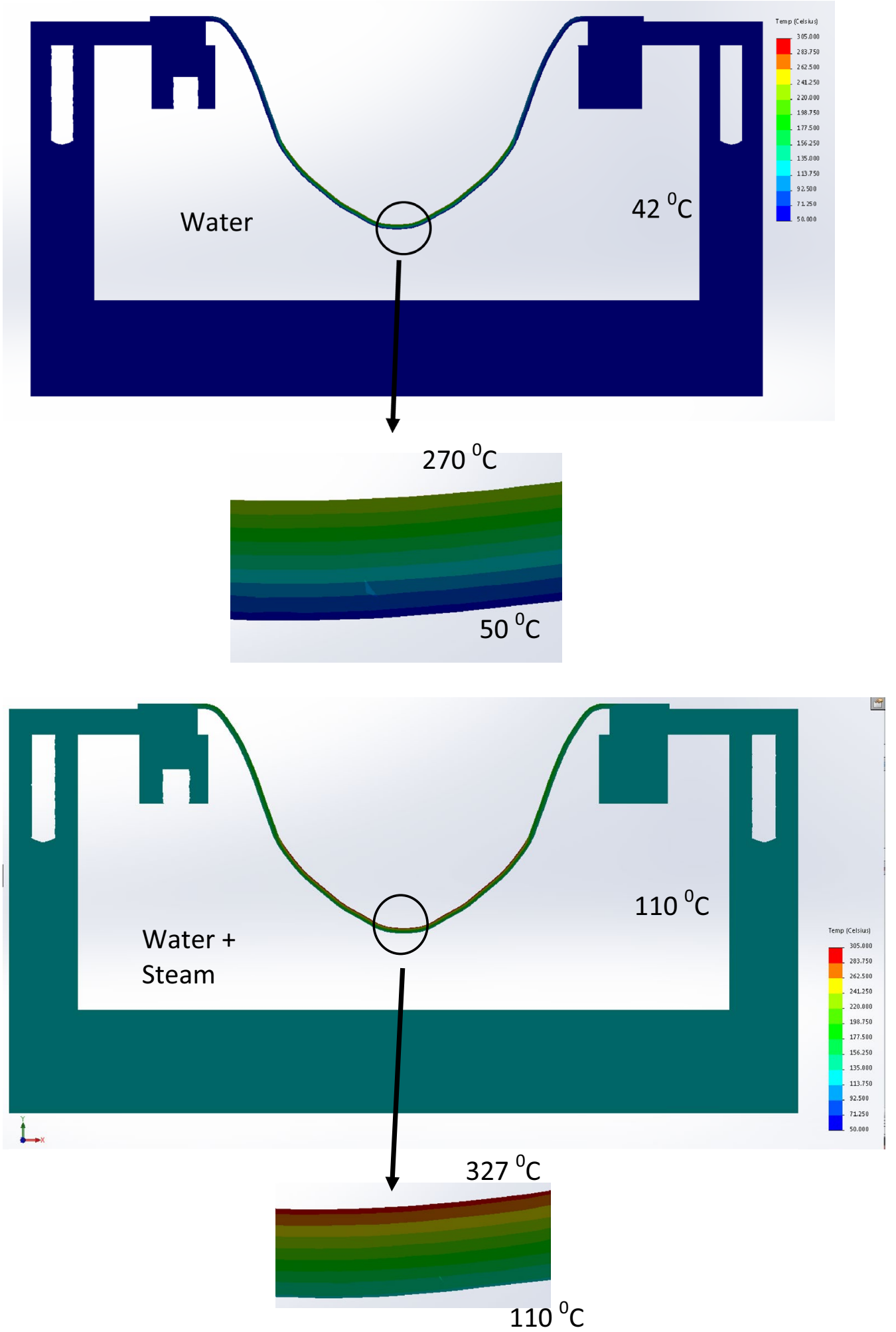

Fig. 7 Contour plots corresponding to $500 \mathrm{~s}$ (above) and $1424 \mathrm{~s}$ (below) 


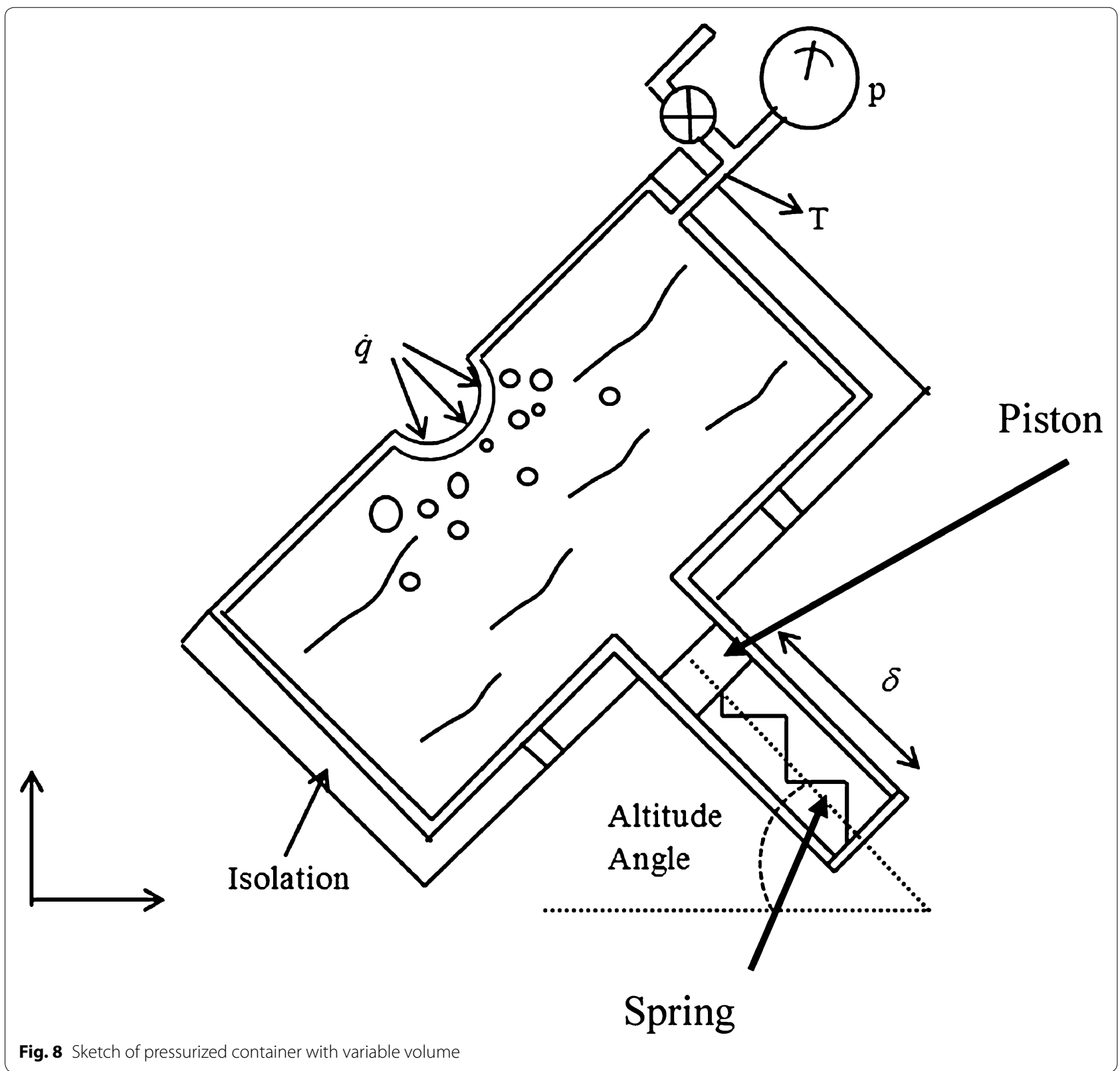

Table 1 Summary of the calculated results

\begin{tabular}{llll}
\hline & Initial & Preloaded & Final \\
\hline Absolute pressure $\left(\times 10^{-1} \mathrm{MPa}\right)$ & 1.01 & 1.39 & 2.50 \\
Temperature $\left({ }^{\circ} \mathrm{C}\right)$ & 100.00 & 109.01 & 126.86 \\
Piston displacement $\left(\times 10^{-2} \mathrm{~m}\right)$ & 0 & 1.37 & 3.67 \\
Spring force $(\mathrm{N})$ & 0 & 23.98 & 64.23 \\
Total volume $\left(\times 10^{-4} \mathrm{~m}^{3}\right)$ & 5.30 & 5.39 & 5.54 \\
Quality $\times\left(\times 10^{-6}\right)$ & 0 & 5 & 30 \\
$u_{f}$ specific internal energy of liquid $(\mathrm{kJ} / \mathrm{kg})$ & 418.75 & 456.97 & 532.89 \\
\hline
\end{tabular}

Since the thermal energy loss through the lens was small (11\%), the Fresnel lens was highly efficient at collecting the sun direct normal irradiance. Efficiencies on the order of $50 \%$ were obtained for water boiling. Higher efficiencies may be reached by using more optimized commercial absorbers and better isolation techniques. The approach to follow would depend on the availability and cost effectiveness of the components for the intended application.

The unique capability of the Fresnel lens to concentrate thermal energy has the potential to affect future research 
into many global issues. The intense heat generated at the focus is a source for clean energy as well as clean water production. Potential research applications could range from as varied applications as surface treatments of metals (Sierra and Vazquez 2004) to waste disposal by high level temperature incinerators.

\section{Competing interests}

The author declare that he has no competing interests.

Received: 7 April 2015 Accepted: 4 January 2016

Published online: 26 January 2016

\section{References}

Airlight Energy Co (2014). Airlight Energy solution. Solving the Energy Crisis One Sunflower at a Time. http://www.airlight.energy/?page_id=42. Accessed 10 Jan 2015.

BHLens Co. Application of Fresnel Lens. http://www.BHLens.com. Accessed 11 Feb 2014

Awad, C. (2012). Enhancing the Solar Water Disinfection (SODIS) Method Using a Fresnel Lens. MS Thesis, University of Californnia Riverside. https:// escholarship.org/uc/item/07m1d7rt. Accessed 10 May 2014.

Chu, Y. (2011). Review and comparison of different solar energy technologies. Global Energy Network Institute (GENI), San Diego. http://66.240.244.113/ globalenergy/research/review-and-comparison-of-solar-technologies/ Review-and-Comparison-of-Different-Solar-Technologies.pdf.
Fresnel Technologies, Inc. http://www.fresneltech.com. Accessed 5 Mar 2014. Kalogirou, S. A. (2004). Solar thermal collectors and applications. Progress in Energy and Combustion Science, 30(3), 231-295.

Kumar, V., Shrivastava, R. L., \& Untawale, S. P. (2015). Fresnel lens: a promising alternative of reflectors in concentrated solar power. Renewable and Sustainable Energy Reviews, 44, 376-390.

Madhugiri, G. A., \& Karale, S. R. (2012). High solar energy concentration with a Fresnel lens: a Review. International Journal of Modern Engineering Research, 2(3), 1381-1385.

National Renewable Energy Laboratory (NREL). Measurement and Instrumentation Data Center. Solar position and intensity from time and place. http://www.nrel.gov/midc/solpos/. Accessed 20 June 2014.

NREL. National Solar radiation Database 1991-2010 update. Reading and Understanding Database Products. http://rredc.nrel.gov/solar/old_data/ nsrdb/1991-2010/. Accessed 20 June 2014.

Sierra, C., \& Vázquez, A. J. (2005). High solar energy concentration with a Fresnel lens. Journal of materials science, 40(6), 1339-1343.

Tian, Y., \& Zhao, C. Y. (2013). A review of solar collectors and thermal energy storage in solar thermal applications. Applied Energy, 104, 538-553.

Tuttnauer Co., Medical Autoclaves Sterilization Programs. http://www. tuttnauerusa.com/products/officebased-practices/medical-autoclaves. Accessed 1 Apr 2015.

United States Naval Office (USNO). Astronomical Applications Department. Sun or Moon Altitude/Azimuth calculation. http://aa.usno.navy.mil/data/ docs/AltAz.php. Accessed 30 July 2014.

Xie, W. T., Dai, Y. J., Wang, R. Z., \& Sumathy, K. (2011). Concentrated solar energy applications using Fresnel lenses: a review. Renewable and Sustainable Energy Reviews, 15(6), 2588-2606.

\section{Submit your manuscript to a SpringerOpen ${ }^{\odot}$ journal and benefit from:}

- Convenient online submission

- Rigorous peer review

- Immediate publication on acceptance

- Open access: articles freely available online

- High visibility within the field

- Retaining the copyright to your article

Submit your next manuscript at $\boldsymbol{~ s p r i n g e r o p e n . c o m ~}$ 